\title{
Developing Nursing Care Standards for Venous Thromboembolism (VTE) for Patients with Orthopedic Surgery
}

\author{
Mona H. Ahmed, Mohammed A. Moubarak, Hala M. Ghanem \& Sahra Z. Azer. \\ Nursing Supervisor Students Hospital, Assiut University Egypt. \\ Professor of Vascular Surgery Department, Faculty of Medicine, Assiut University Egypt. \\ Assistant Prof. Medical Surgical Nursing Adult Nursing, Faculty of Nursing, Assiut University Egypt. \\ Lecturer of medical-surgical Nursing Adult Nursing, Faculty of Nursing, Assiut University Egypt.
}

\begin{abstract}
Aims of this study; Develop nursing care standards for venous thromboembolism for patient with orthopedic surgery. Subjects and method; Descriptive exploratory research design were utilized to conduct this study. This study was conducted in the Trauma Unit at Assiut University Hospital. The study sample of all available nurses 30 working in Internal Trauma Unit who were willing to participate in the study, in addition to patients 30 who had performed orthopedic surgery. Tools; nurses knowledge questionnaire sheet, nurses practice observation checklist sheet, basic nurse's opinionnaire sheet and patient assessment sheet. Results; Showed that; all of nurses had poor knowledge regarding nursing care standard of venous thromboembolism in orthopedic surgery patients and inadequacy in their practice. Majority of patient with pelvic fracture, lower limb fracture, repair of open fracture femur and hip fracture. Conclusion; All nurses had poor knowledge and inadequacy in their practice about nursing care standard of venous thromboembolism in orthopedic surgery patient. Recommendation; Application of the nursing care standards for venous thromboembolism in orthopedic surgery patients in service training program for nurses is important in trauma unit.
\end{abstract}

\section{Keywords: Nursing Care Standards, Venous Thromboembolism \& Orthopedic Surgery Department.}

\section{Introduction}

Deep vein thrombosis (DVT) and pulmonary embolism (PE) are two aspects of one disease process known as venous thromboembolism (VTE). In DVT, a thrombus (blood clot) forms in the deep veins of the leg or pelvis. In PE, some or all of the thrombus becomes detached and moves from the vein through the right side of the heart to lodge in one or more pulmonary arteries (Smeltzer et al., 2010).

Venous thrombosis is a disease affecting 1-2 / 1000 persons/ year The most common sites of thrombosis are deep vein thrombosis (DVT) of the leg or pelvis or pulmonary embolism, less frequent sites include the portal vein, the splanchnic vein, cerebral veins and the veins of the upper extremity (Reitsma, 2012). The incidence of VTE is slightly higher in men than in women, but at a younger age, women have a higher incidence probably due to pregnancy and female hormonal intake. Both men and women have an age dependent increasing risk of VTE but men seem to have a higher incidence than women after the age of 60 years (Anderson \& Weitz, 2010).

Patients undergoing orthopedic surgeries, particularly older patients having total hip arthroplasty (THA), total knee arthroplasty (TKA), or hip fracture surgery is at a higher risk for DVT than younger patients who have diagnostic arthroscopy. One factor contributing to the formation of DVT in orthopedic cases is the positioning of the extremity during surgery. Also, retracting soft tissue and femoral and iliac vein compression can damage vessel walls (AACP), 2012).

Use of modern methods of DVT prophylaxis and treatment will reduce the incidence of DVT during the postoperative period by two-thirds and will prevent death from pulmonary embolism in 1 patient out of every 200 orthopedics surgerical operations, prophylaxis is preferred to treatment, as venous thromboembolism can be hard to diagnose and, in the case of PE, there is often no warning that the patient is at risk. Death due to PE is often immediate or occurs within 1 to 2 hours of onset. In high-risk groups of patients, it is more cost effective to protect against DVT and PE than to treat these conditions when they occur (Rocha et al., 2006).

Standards of practice are essential because they serve as guidelines for providing and evaluating nursing care. Orthopedic surgery care standards have been developed to assist clinician in the management of people who have orthopedic surgery. It includes care from pre-operative through long term community care (Zidarov et al., 2009).

A Standard is defined as benchmark of achievement, which is based on a desired level of excellence. It reflects a desired and achievable level of performance against which actual performance can be compared. It provides a guide to the knowledge, skills, judgment 
$\&$ attitudes that are needed to practice safely and help to ensure high quality care (Arun, 2009).

A standard of care holds a person of exceptional skill or knowledge to a duty of acting as would a reasonable and prudent person possessing the same or similar skills or knowledge under the same or similar circumstances. Standards of care may serve as guidelines when evaluating nursing care for possible negligence. They define acts that are permitted to be performed or prohibited from being performed. It gives direction to the nurse - defining what should or should not be done for patients (Bickley, 2007).

\section{Significance of the study}

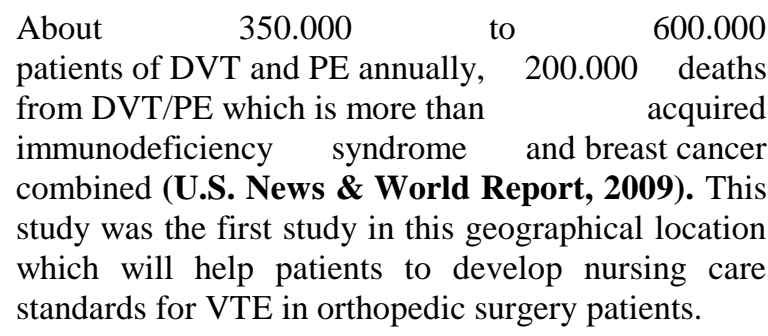

\section{Aims of the study}

This study aim is a develop nursing care standards regarding venous thromboembolism (VTE) for patients with orthopedic surgery throw

1. Assess nurses' knowledge.

2. Assess nurses' practices.

3. Develop nursing care standards based on patient need.

\section{Research question}

Is the developing nursing care standard of venous thromboembolism (VTE) effect on patients with orthopedic surgery?

\section{Subjects and Methods}

Research design; Descriptive research designs were utilized in this study.

Setting; This study was conducted in the Trauma Unit at Assiut University Hospital.

Subjects; A sample of all available nurses (30) worked in Trauma Unit who were participate in the study, in addition to patients (30) who had performed orthopedic surgery; inclusion criteria: orthopedic surgery patients with fractures of the lower limbs and pelvic who were conducted the surgery for fixation; both sexes and age range between 18-65.

Tools; Four tools were used in this study and developed by the researcher to collect the necessary data for this study.

Tool I: Nurses knowledge questionnaire sheet; this sheet was developed by the researcher based on current national and international literature to assess nurses' knowledge as regarded VTE. It included three parts:-

Part I: Socio-demographic data; this part was concerned with the socio demographic characteristics of the nurses. It included the gender, age, marital status, level of education, and years of experience and trained courses. It included 7 questions (from 1:7).

Part II: Assessment of nurses' knowledge about (VTE); this part included definition of VTE, sites of venous blood clots whole of the body, the high risk patient of the VTE, definition of DVT, signs and symptoms of DVT, definition of the PE, signs and symptoms of the PE, how to diagnose VTE, the complications of VTE, types of VTE prophylaxis, complications of that prophylaxis, the contraindications of anti-coagulant medication, mention the orthopedic surgery that causes of VTE and indicate levels of risk factors for orthopedic surgery patients. It included 14 questions (from 8:21). Part III: Assessment of nurses' knowledge about Nurses' standards practice for patient with (VTE) in orthopedic surgery patient; this part included nursing intervention (before surgery, in the recovery room, on the first day after surgery), assessment of neurovascular status for orthopedic patients, apply elastic compression stocking, implementation of intervention for patients with DVT and health education for patients with orthopedic surgery before hospital discharge. It included 6 questions (from 22:27).

Scoring system; the total number of questions was (27). The total scores were (100). Those who obtained less than $50 \%$ were considered have poor level. While those who obtained $50-70 \%$ were considered have fair level and those who obtained more than $70 \%$ were considered have good level.

Tool II: Nurses practice observation checklist sheet; observational checklists were developed to assess the practical aspects of the nurses intervention related to VTE in orthopedic surgery patient. It is consists of four parts

Part I: Pre operative nursing intervention; this part included the followed: on admission:-assessed the patient for risk factor of VTE, assessed the patient for risk factor of bleeding before started VTE prophylaxis, hand washed and measured vital signs, preoperative teaching :-coughing and breathing exercise, leg exercise and applying anti-embolism stocked. It included 73 questions (from 1:73).

Part II: Immediately post operative nursing intervention; this part was included assessment of patient's respiratory function and assesses fluid intake and output. It included 25 questions (from 74:98).

Part III: Routine post-operative nursing intervention; this part includes the followed: Provide routine postoperative nursing care: deep breathing, 
intravenous (IV) and oral fluid administration, assess neurovascular status, giving medication and anticoagulation, assessed signs and symptoms of VTE, use elastic compression stocking, position the patient comfortably, assist the patient into a chair, assess popliteal, dorsalis pedis, and posterior tibial pulses, assess skin temperature of legs, assess for Homans' sign, ankle exercises, monitor body temperature and assessed the patient for sign and symptoms of bleeding. It included 35 questions (from 99:133).

Part IV: Nursing instruction before orthopedic patient discharge; This part includes health education before discharge regarded signs and symptoms, prevention of VTE, VTE prophylaxis measures, complications of drug administration, administration of anti-embolism stocking, leg exercise and follow up. It included 11 questions (from 134:144).

Scoring system; The total number of item of observation checklist sheet was 144, each item in checklist was scored as follow: two degree for each step that done correct (correctly, in time and with the required frequency) and one degree for each step done incorrect (incorrectly, not in time and without the required frequency) and zero for step that not done. Inapplicable means that the nurses were not able to apply the principles of the standard due to shortage in supplies and equipment, not due to shortage or negligence from the nurses.

Tool III: Basic nurse's opinionnaire sheet; A structured opinionnaire was developed in order to elicit opinions of nurses as regard: the basic nurse's for orthopedic surgery patients. This included 7 major items, which were further, subdivided into sub items

1. Ensures that the trauma unit environment is ready to receive the orthopaedic surgery patient.

2. Ensure that the trauma unit environment is safe to receive orthopaedic surgery patient

3. Ensure that continuous monitored and recorded are followed for post operative patients

4. Ensures that all infection control measures are properly followed in all procedures

5. Ensures that all health team are properly for patient care.

6. Ensure that safety for each patient during transportation from operated room to the unit.

7. Ensures that all staff (health team) follows ethics and patients right in the trauma unit.

The scoring system of the nurses' opinionnaire; was as follow

Agree

Disagree

Tool IV: Patient assessment sheet; this sheet was developed by researcher based on the literature review it was consist of three parts;
Part I: Socio demographic data about the patient; Patients' name, age, sex, marital status, occupation, level of education.

Part II: Assessment of patient past history; anemia, chronic heart disease, myocardial infarction, malignancy, varicose veins and previous DVT.

Part III: Assessment of patient current history; trauma, surgical intervention, mobility, thrombo prophylaxis's, assessment of the extremities, the investigation requirement.

The scoring system of the Patient assessment; was as follow: Patient age by years $(18 \leq 30=0,31 \leq 40=1$, $41 \leq 50=2, \quad 51 \leq 65=3)$, patient $\operatorname{sex} \quad($ male $=0$, female $=1$ ), marital status ( divorced $=2$, widowed $=3$ ), occupation (office work= 0 , machinery work $=1$, manual worker $=2$, professional $=3$, not working=4), level of education (high education $=0$, secondary education $=1$, read and write $=2$, illiterate $=3$ ).

\section{Methods}

- An official letter was issued from the Dean of the Faculty of Nursing to the Head of Trauma Unit solicited the necessary approval to conduct the present research after explain the aim of the study to obtain their cooperation.

- Three tools were developed based on recent literature.

- Content validity was established by panel of (5) expertise's from medical and surgical nursed staff.

- Content reliability was estimated by Alpha Cronbach's test and its result was $\mathrm{R}=0.68$

- A pilot study carried out in February 2014 to test the feasibility and practicability of the study tools on $10 \%$ of sample ( 3 nurses and 3 patients).

- Data were collected from Trauma Unit at Assiut University Hospital during the period from March /2014 to May/2014.

- Each nurse and patient was informed with the purpose of the study participation is voluntary.

Limitations of the study

Many barriers during collected data concerned the thesis about assessment of nurse's knowledge and practice related to orthopedic surgery patient at Assiut University Hospital. Barriers such as The flow of patients with other diagnosis was many which make it difficult for nurses to fill the questionnaire sheet which take a lot of time to collect the data, Literature and nursing researches in this unit were inadequate, work in the Trauma Unit is very hard which led to difficulty in supplementing this study on time, there are no enough resources in the unit, The interview takes much time with patients collect the needed data. 


\section{Results}

Table (1): Distribution of the characteristics of the studied nurses $(n=30)$.

\begin{tabular}{|c|c|c|}
\hline Characteristics & No. $(n=30)$ & $\%$ \\
\hline \multicolumn{3}{|l|}{ Gender } \\
\hline Male & 1 & 3.3 \\
\hline Female & 29 & 96.7 \\
\hline \multicolumn{3}{|l|}{ Age: (years) } \\
\hline$<20$ & 2 & 6.7 \\
\hline $20-30$ & 22 & 73.3 \\
\hline$\geq 30$ & 6 & 20.0 \\
\hline Mean \pm SD & \multicolumn{2}{|c|}{$28.1 \pm 9.1$} \\
\hline \multicolumn{3}{|l|}{ Marital status } \\
\hline Single & 11 & 36.7 \\
\hline Married & 15 & 50.0 \\
\hline Divorced & 3 & 10.0 \\
\hline Widowed & 1 & 3.3 \\
\hline \multicolumn{3}{|l|}{ Level of education } \\
\hline Diploma of nursing & 19 & 63.3 \\
\hline Institute Technician Nursing & 7 & 23.3 \\
\hline Bachelor of nursing & 4 & 13.3 \\
\hline \multicolumn{3}{|l|}{ Years of experience } \\
\hline$<1$ & 4 & 13.3 \\
\hline $1-2$ & 8 & 26.7 \\
\hline$>2$ & 18 & 60.0 \\
\hline Mean \pm SD & \multicolumn{2}{|c|}{$3.5 \pm 1.8$} \\
\hline \multicolumn{3}{|l|}{ Attending training courses } \\
\hline Yes & 3 & 10.0 \\
\hline No & 27 & 90.0 \\
\hline
\end{tabular}

Table (2): Distribution of total score of nurses' knowledge about (VTE) in orthopedic surgery patient (n=30).

\begin{tabular}{|l|c|c|}
\hline Nurses' knowledge & No. & \% \\
\hline Poor & 28 & 93.3 \\
\hline Fair & 2 & 6.7 \\
\hline Good & 0 & 0.0 \\
\hline Total & $\mathbf{3 0}$ & $\mathbf{1 0 0}$ \\
\hline
\end{tabular}

Table (3): Percentage distribution of total score of nurses' Knowledge about nursing intervention for (VTE) of orthopedic surgery patients $(n=30)$.

\begin{tabular}{|c|c|c|}
\hline Nurses' knowledge & No. & \% \\
\hline Poor & 30 & 100.0 \\
\hline Fair & 0 & 0.0 \\
\hline Good & 0 & 0.0 \\
\hline Total & $\mathbf{3 0}$ & $\mathbf{1 0 0}$ \\
\hline
\end{tabular}


Table (4): Distribution of nurses' practice as regarding nursing intervention for (VTE) in orthopedic surgery patient $(n=30)$.

\begin{tabular}{|c|c|c|c|c|c|c|c|c|}
\hline \multirow{3}{*}{ Nurses practice } & \multicolumn{4}{|c|}{ Done } & \multirow{2}{*}{\multicolumn{2}{|c|}{ ND }} & \multirow{2}{*}{\multicolumn{2}{|c|}{ NA }} \\
\hline & \multicolumn{2}{|c|}{$\mathbf{C}$} & \multicolumn{2}{|c|}{$\mathbf{I}$} & & & & \\
\hline & No. & $\%$ & No. & $\%$ & No. & $\%$ & No. & $\%$ \\
\hline \multicolumn{9}{|l|}{ I. Pre-operative nursing intervention } \\
\hline \multicolumn{9}{|l|}{ 1.On admission } \\
\hline a- assessing the patient for risk factor of VTE. & 0 & 0.0 & 0 & 0.0 & 30 & 100.0 & 0 & 0.0 \\
\hline $\begin{array}{l}\text { b- Assessing the patient for risk factor of } \\
\text { bleeding before started VTE prophylaxis. }\end{array}$ & 0 & 0.0 & 0 & 0.0 & 30 & 100.0 & 0 & 0.0 \\
\hline c-Hand washing & 0 & 0.0 & 2 & 6.6 & 28 & 93.4 & 0 & 0.0 \\
\hline \multicolumn{9}{|l|}{ 2. Measuring vital signs } \\
\hline a Temperature & 0 & 0.0 & 3 & 10.0 & 27 & 90.0 & 0 & 0.0 \\
\hline b- Pulse & 0 & 0.0 & 0 & 0.0 & 30 & 100.0 & 0 & 0.0 \\
\hline c- Blood pressure & 0 & 0.0 & 0 & 0.0 & 30 & 100.0 & 0 & 0.0 \\
\hline d- Respiration & 0 & 0.0 & 0 & 0.0 & 30 & 100.0 & 0 & 0.0 \\
\hline \multicolumn{9}{|l|}{ 3. Pre-operative teaching } \\
\hline a- Coughing and breathing exercise & 0 & 0.0 & 0 & 0.0 & 30 & 100.0 & 0 & 0.0 \\
\hline b- Leg exercise: & 1 & 3.3 & 0 & 0.0 & 29 & 96.7 & 0 & 0.0 \\
\hline c- Applying anti-embolism stocking: & 0 & 0.0 & 0 & 0.0 & 0 & 0.0 & 30 & 100.0 \\
\hline \multicolumn{9}{|l|}{ II. Immediate Post-operative nursing intervention } \\
\hline \multicolumn{9}{|l|}{ 1. Assess patient's respiratory function } \\
\hline a- Maintaining patent airway & 0 & 0.0 & 0 & 0.0 & 30 & 100.0 & 0 & 0.0 \\
\hline b- Administer oxygen therapy if needed & 0 & 0.0 & 0 & 0.0 & 25 & 83.3 & 5 & 16.7 \\
\hline $\begin{array}{l}\text { 2. Assess fluid intake and output to } \\
\text { prevent dehydration: }\end{array}$ & 0 & 0.0 & 0 & 0.0 & 30 & 100.0 & 0 & 0.0 \\
\hline III. Routine post-operative nurses' intervention & 1 & 3.3 & 8 & 26.7 & 20 & 66.7 & 1 & 3.3 \\
\hline $\begin{array}{l}\text { V. Health education for patients before } \\
\text { discharge }\end{array}$ & 2 & 6.6 & 5 & 16.7 & 20 & 66.7 & 3 & 10.0 \\
\hline
\end{tabular}

Table (5): Distribution of nurses' competencies' for (VTE) in orthopedic surgery patient $(n=30)$ :

\section{Nurses opinions}

\begin{tabular}{|c|c|c|c|}
\hline \multicolumn{2}{|c|}{ Agree } & \multicolumn{2}{c|}{ Disagree } \\
\hline No. & $\%$ & No. & $\%$ \\
\hline
\end{tabular}

I- Ensures that the trauma unit environment are ready to receive the orthopedic surgery patient

\begin{tabular}{|l|c|c|c|c|}
\hline 1. Prepare the trauma unit with the necessary equipment. & 28 & 93.3 & 2 & 6.7 \\
\hline $\begin{array}{l}\text { 2. Prepare the car table with basic instrument according to } \\
\text { patient condition. }\end{array}$ & 29 & 96.7 & 1 & 3.3 \\
\hline 3. Prepare patient room. & 28 & 93.3 & 2 & 6.7 \\
\hline 4. Component of Trauma unit. & 29 & 96.7 & 1 & 3.3 \\
\hline II- Ensure that the trauma unit environment are safe to receive orthopedic surgery patient \\
\hline 1. Identifying your patient. & 30 & 100.0 & 0 & 0.0 \\
\hline 2. Preventing patient falls by. & 29 & 96.7 & 1 & 3.3 \\
\hline 3. Reporting accidents and errors. & 29 & 96.7 & 1 & 3.3 \\
\hline 4-Maintaining safe environment post-operative. & 28 & 93.3 & 2 & 6.7 \\
\hline $\begin{array}{l}\text { 5. Maintaining safe environment in administration of } \\
\text { medication. }\end{array}$ & 30 & 100.0 & 0 & 0.0 \\
\hline
\end{tabular}




\begin{tabular}{|c|c|c|c|c|}
\hline \multirow{2}{*}{ Nurses opinions } & \multicolumn{2}{|c|}{ Agree } & \multicolumn{2}{|c|}{ Disagree } \\
\hline & No. & $\%$ & No. & $\%$ \\
\hline \multicolumn{5}{|c|}{ III- Ensure that continuous monitoring and recording are followed for post-operative patients } \\
\hline 1. Pre operative period & 30 & 100.0 & 0 & 0.0 \\
\hline 2. Immediate post operative period & 29 & 96.7 & 1 & 3.3 \\
\hline 3. Routine post operative period. & 29 & 96.7 & 1 & 3.3 \\
\hline 4. Discharge advice. & 30 & 100.0 & 0 & 0.0 \\
\hline \multicolumn{5}{|c|}{ III- Ensures that all infection control measures are properly followed in all procedures } \\
\hline 1. Principle of aseptic technique in all procedure. & 30 & 100.0 & 0 & 0.0 \\
\hline 2. Identify and supervise methods of disinfecting the following. & 30 & 100.0 & 0 & 0.0 \\
\hline 3. Using universal precaution. & 30 & 100.0 & 0 & 0.0 \\
\hline $\begin{array}{l}\text { V- Ensures that all health team are properly for patient } \\
\text { intervention. }\end{array}$ & 30 & 100.0 & 0 & 0.0 \\
\hline $\begin{array}{l}\text { VI- Ensure that safety for each patient during } \\
\text { transportation from operating room to unit. }\end{array}$ & 30 & 100.0 & 0 & 0.0 \\
\hline $\begin{array}{l}\text { VII- Ensures that all staff (health team) follows ethics and } \\
\text { patients right in the trauma unit. }\end{array}$ & 30 & 100.0 & 0 & 0.0 \\
\hline
\end{tabular}

Table (6): Distribution of the studied patients characteristics $(n=30)$.

\begin{tabular}{|c|c|c|}
\hline Characteristics & No. $(n=30)$ & $\%$ \\
\hline \multicolumn{3}{|l|}{ Gender } \\
\hline Male & 16 & 53.3 \\
\hline Female & 14 & 46.7 \\
\hline \multicolumn{3}{|l|}{ Age: (years) } \\
\hline $18 \leq 30$ & 12 & 40.0 \\
\hline $31 \leq 40$ & 8 & 26.7 \\
\hline $41 \leq 50$ & 8 & 26.7 \\
\hline $51 \leq 65$ & 2 & 6.6 \\
\hline \multicolumn{3}{|l|}{ Marital status } \\
\hline Single & 10 & 33.3 \\
\hline Married & 17 & 56.7 \\
\hline Divorced & 0 & 0.0 \\
\hline Widowed & 3 & 10.0 \\
\hline \multicolumn{3}{|l|}{ Level of education } \\
\hline High education & 0 & 0.0 \\
\hline Secondary education & 12 & 40.0 \\
\hline Read and write & 10 & 33.3 \\
\hline Illiterate & 8 & 26.7 \\
\hline \multicolumn{3}{|l|}{ Occupational status } \\
\hline Office work & 1 & 3.3 \\
\hline Machinery work & 1 & 3.3 \\
\hline Manual worker & 6 & 20.0 \\
\hline Professional & 3 & 10.0 \\
\hline Not working & 19 & 63.4 \\
\hline
\end{tabular}


Table (7): Relation between patients' medical data (Current history) and their age and sex $(n=30)$.

\begin{tabular}{|c|c|c|c|c|}
\hline \multirow{2}{*}{ Items } & \multicolumn{2}{|c|}{ Age } & \multicolumn{2}{|c|}{ Sex } \\
\hline & F-test & P-value & F-test & P-value \\
\hline \multicolumn{5}{|l|}{ I- Trauma } \\
\hline 1. Head & - & - & - & - \\
\hline 2. Chest & - & - & - & - \\
\hline 3. Spinal & - & - & - & - \\
\hline 4. Pelvic & 0.564 & 0.644 & 0.913 & 0.413 \\
\hline 5. Lower limb & 1.040 & 0.391 & 0.706 & 0.503 \\
\hline \multicolumn{5}{|l|}{ II- Surgical intervention } \\
\hline 1. Repair of small fracture. & 0.473 & 0.704 & 0.420 & 0.661 \\
\hline 2. $\quad$ Arthroscopy. & - & - & - & - \\
\hline 3. Postoperative plaster cast of tibia fracture. & 0.908 & 0.451 & 3.900 & $0.033 *$ \\
\hline 4. $\quad$ Repair of open femur fracture. & 0.166 & 0.919 & 0.136 & 0.873 \\
\hline 5. Repair of hip fracture. & 0.523 & 0.670 & 0.722 & 0.495 \\
\hline 6. Hip arthroplasty. & 0.473 & 0.704 & 0.420 & 0.661 \\
\hline 7. $\quad$ Knee arthroplasty. & - & - & - & - \\
\hline 8. Injury of spinal cord. & - & - & - & - \\
\hline \multicolumn{5}{|l|}{ III- Mobility } \\
\hline 1. Ambulant. & - & - & - & - \\
\hline 2. $\quad$ Limited (users aids self). & 0.540 & 0.695 & 1.454 & 0.251 \\
\hline 3. Very limited (needs help). & 1.191 & 0.333 & 1.458 & 0.250 \\
\hline 4. $\quad$ Chair bound. & 0.473 & 0.704 & 0.420 & 0.661 \\
\hline 5. Complete bed rest & 0.904 & 0.453 & 1.417 & 0.260 \\
\hline \multicolumn{5}{|l|}{ V. Thromboprophylaxis } \\
\hline 1. Leg elevation. & 1.016 & 0.402 & 1.454 & 0.251 \\
\hline 2. Graduated elastic compression stockings (GECS). & - & - & - & - \\
\hline 3. Intermittent pneumatic compression & - & - & - & - \\
\hline 4. Heparin. & - & - & - & - \\
\hline 5. Low molecular weight heparin. & 0.338 & 0.798 & 2.571 & 0.095 \\
\hline 6. Warfarin. & 0.473 & 0.704 & 0.420 & 0.661 \\
\hline 7. Others: & - & - & 0.420 & 0.661 \\
\hline 8. No prophylaxis & 0.793 & 0.690 & - & - \\
\hline \multicolumn{5}{|l|}{ VI. Assessment of the extremities } \\
\hline 1. Swelling. & 0.493 & 0.690 & 2.114 & 0.140 \\
\hline 2. Warmth. & 0.908 & 0.451 & 0.420 & 0.661 \\
\hline 3. $\quad$ Pain. & 0.473 & 0.704 & 0.420 & 0.661 \\
\hline 4. $\quad$ Redness. & - & - & - & - \\
\hline 5. Low grad fever. & - & - & - & - \\
\hline $\begin{array}{ll}6 . & \text { Tenderness. }\end{array}$ & - & - & - & - \\
\hline 7. Cyanosis. & - & - & - & - \\
\hline 8. Homan's sign. & - & - & - & - \\
\hline \multicolumn{5}{|l|}{ VII- The investigation requirement } \\
\hline 1. Venous Doppler ultrasonography (DUS). & 1.254 & 0.311 & 5.584 & $0.009 * *$ \\
\hline 2. Impedance plethesmography. & - & - & - & - \\
\hline 3. Computed tomography (CT). & 0.523 & 0.670 & 5.584 & $0.009 * *$ \\
\hline 4. $\quad$ Contrast venography. & 0.908 & 0.451 & 1.773 & 0.189 \\
\hline
\end{tabular}




\begin{tabular}{|l|c|c|c|c|}
\hline \multicolumn{2}{|c|}{ Items } & \multicolumn{2}{c|}{ Age } & \multicolumn{2}{c|}{ Sex } \\
\cline { 2 - 5 } & F-test & P-value & \multicolumn{1}{c|}{ F-test } & P-value \\
\hline \multicolumn{2}{|l|}{ Laboratory } & & & \\
\hline A. Complete blood cell account: & - & - & 1.000 & 0.381 \\
\hline - RBC. & - & - & - & - \\
\hline - WBC. & - & - & - & - \\
\hline - HG. & - & - & - & - \\
\hline - Platelet. & - & - & - & - \\
\hline - Hematocrit. & - & - & - & - \\
\hline B. Activate partial thromboblastin time (aPTT). & - & - & - & - \\
\hline C. A prothrombin time (PT). & - & - & - & - \\
\hline D. International normalized ratio (INR). & - & - & - \\
\hline
\end{tabular}

Table (1) : Shows that; more than two third $73.3 \%$ of nurses their age ranged from $20-30$ years. $50.0 \%$ of them were married. Most of them $63.3 \%$ had diploma of nursing, $60 \%$ of them had $>2$ years of experience, 90\% had not attended training programs.

Table (2) : Vast majority of nurses (93.3\%) had poor level of knowledge as regarding venous thromboembolism (VTE).

Table (3) : This table shows that; all nurses (100.0\%) had poor level knowledge about nursing intervention for venous Thromboembolism (VTE) for orthopedic surgery patient.

Table (4) : This table cleared that; the vast majority of nurses hadn't done standards practice of nurses providing intervention for (VTE) for orthopedic surgery patient.

Table (5) : This table shows that: the vast majority of nurses agreed the basic nursing competencies for (VTE) for orthopedic surgery patient.

Table (6) : This table shows that; more than half of patients $53.3 \%$ are male, $40.0 \%$ of patients their age ranged from $18-30$ years, $56.7 \%$ of them were married, $40.0 \%$ of them are secondary education and $63.4 \%$ of them are not working.

Table (7) : Shows that; there are statistical significant relation between patients' sex and their current medical history in (Postoperative plaster cast of tibia fracture) with $\mathrm{p}$-value (0.033). There is highly statistical significant relation between patients' sex and their current medical history in (Venous Doppler ultrasonography (DUS) and Computed tomography (CT) with p-value (0.009).

\section{Discussion}

Based on the results of the present study, the majority of the nurses their ages ranged from 20-30 years half of them are married and have diploma of nursing. The majority of them their experiences more than 2 years. The majority of them had no attended training program.

Ahmed, (2011); in the same line with the current study findings conducted a study in kidney dialysis unit of Assiut University Hospital entitled "Effect of designed nursing protocol on nurse's knowledge and practice regarding haemodialysis patients" the majority of the nurses were married, female, their age ranged from 20-30 years, have a diploma qualification, years of experiences in haemodialysis units ranged from 20-30 and have in-service training courses related to infection control precautions.

Furthermore, the result of this study revealed that the vast majority of nurses had poor level of knowledge as regarding (VTE) for orthopedic surgery patient. Minority of nurses had fair level of knowledge as regarding (VTE) in orthopedic surgery patient. This result incongruent with (Marquis \& Huston, 2009): who found that good level of knowledge regarding blood borne infection, especially HIV\& AIDs. In a more recent study exploring nurse's knowledge of universal precautions (Marquis \& Huston, 2009): reported that knowledge was good and agreed with (Gamal, 2005) who found that the level of knowledge among nurses was poor regarding universal infection control precautions while the present study showed that all of nurses had poor knowledge about nursing care standard for (VTE) in orthopedic surgery patient.

This interpretation is in agreement with Samer, (2005) who stated that the nurses concern in their work on the routine nursing care. This result disagree with Dianne McMahon, (2011) stated that the nurse is responsible and accountable for the quality of nursing care given to patients. The single most important protective strategy for the nurse is to be a knowledgeable and safe practitioner of nursing and to meet the standards of care with all patients. Nurses are 
empowered by the society of care and the trust of the physician and the patient to ensure quality care.

Based on the results of the present study, the majority of the nurses hadn't done standards practice of nurses providing care for patient with (VTE) for orthopedic surgery patient.

Furthermore, this is in accordance with Dawooda, (2010) who mentioned that nurses are lacking in theoretical and practical skills needed for patient assessment. Other factors that affect nurse's practice are the shortage of the nurse's number, and overlapping of nursing activities especially in morning shifts due to absence and ignorance of clear job description. This interpretations in the same line with Ead, (2007) who stated that lack of nurse' practice related to absence of definite job description and policy.

As regard The majority of nurses had agreed about ensure that the trauma unit environment are ready to receive the orthopedic surgery patients.

This result was in line with fortunato, (2007) who stated that the nurses should prepare the basic equipment for receiving post operative orthopedics surgery patients.

University of Virginia health system professional nursing staff organization, (2011) assured that, environmental Services' work to maintain cleanliness of the patient care and work environments is key to infection control and safety as well as the pleasant atmosphere of the patient care areas. Significant feedback on the part of nursing staff and management was instrumental in the institution deciding to change its contract to another vendor. Also, with a main hospital building constructed in 1989, remodeling, renovation and expansion are constantly underway to improve space and services. Nursing staff and managers have major input into the renovation designs, to help identify the best pattern of patient flow, ensure space for patient care and staff/administrative functions, and promote the convenient placement of fixtures and resources - even improving lighting levels.

As regard this study; more than half of patient are male, married, not working, 40\% of patient their age ranged from 18-30 years, secondary education, all patients had no past history.

As regard this study there are statistical significant relation between patients' sex and their current medical history in Postoperative plaster cast of tibia fracture and in Venous Doppler ultrasonography (DUS) and Computed tomography (CT).

\section{Conclusions}

Based on finding of this study, it can be concluded that:

$\checkmark$ All of nurses had poor knowledge regarding nursing care standards for (VTE) in orthopedic surgery patient.

$\checkmark$ All nurses showed inadequacy in their practice about nursing care standards for (VTE) in orthopedic surgery patient.

$\checkmark$ The majority of nurses had agreed as regarding; the basic nurse's for orthopedic surgery patients. This included 7 major items, which were further, subdivided into sub items

$\checkmark$ All patients had no past history of (VTE), no trauma (head, chest, and spinal) and no mobility.

\section{Recommendations}

Based on the findings of the present study the following recommendations are suggested:

\section{A. For the nurses}

The nurse should be aware that the application of nursing care standards for (VTE) in orthopedic surgery patients:-

- Facilitate achievement of established nursing goals.

- Improves nurse's knowledge, attitude, skills and their ability to help those patients

- Measures nursing competency and evaluate the quality of nursing services.

- Helps in early detection and prevention of complication.

B. For patients

1. Patients are to be provided with sufficient relevant written information to remind them about what they can or cannot do to assist them to cope with the treatment.

2. Patients are to be provided with sufficient information about signs and symptoms of the potential complications and the importance for seeking rapid medical advice.

\section{References}

1. Ahmed, G., (2011): Effect of designed nursing protocol on nurses' knowledge and practice regarding haemodialysis patients. Thesis submitted for partial fulfillment of the requirements of the master degree in adult nursing, Faculty of nursing, Assiut University, Discussion part P. (54).

2. American College of Chest Physicians (AACP), (2012): Antithrombotic therapy and prevention of thrombosis, evidence-based clinical practice guidelines. Chest; $9^{\text {th }}$ ed, 2 suppl. 
3. Anderson J., Weitz J., (2010): Hypercoagulable states. Clinics in chest medicine; ed. $4^{\text {th }}$; Pp. (659).

4. Arun, S., (2009): Manipal College of nursing, Manipal University from: http://currentnursing.com/reviews/nursing_stand ards.htm

5. Bickley. B., (2007) : Guide to Physical Examination and Health History Taking, 9th ed., Philadelphia, Lippincott Williams and Wilkins,chap.32, pp.1337-1342.

6. Dawooda T., (2010): Esablishing Basic Standards of Nursing Care for faciomaxillary patients Undergoing Surgeries. Thesis submitted for partial fulfillment of the requirements of the master degree in adult nursing, Faculty of nursing, Assiut University, Discussion part Pp. (76).

7. Dianne. M., (2011): HG.Org World Wide Legal Directories.www.HGExperts.com.

8. Ead A. (2007): Developing Standards of Intra operative Nursing Interventions for General Surgery Pp. (65).

9. Fortunato. N., (2007): operating room technique, $11^{\text {th }}$ ed. St louis : Mosby

10. Gamal L., (2005): Establishing standards for prevention of nosocomial infection in the recovery rooms and surgical ward at El-minia university Hospital thesis submitted for partial fulfillment of the requirements of the master degree in adult nursing, Faculty of nursing, Assiut University, Discussion part Pp. (75).

11. Marquis L., Bessie\& Huston J., \& Carol., (2009): Leader ship roles\& management functions in nursing, 6 ed, Lippincott, Hong Kong Pp. (371).

12. Reitsma P., Versteeg H., \& Middeldorp S., (2012): Mechanistic view of risk factors for venous thromboembolism. Arterioscler Thromb Vasc Biol.; ed. $3^{\text {th }}$; Pp. (563).

13. Rocha A., de Vasconcellos A., \& da Luz Neto E., (2006) : Risk of venous thromboembolism and efficacy of thrombo prophylaxis in hospitalized obese medical patients and in obese patients undergoing bariatric surgery. $16^{\text {th }}$ ed Pp. (1645-1655).

14. Samer. A., (2005):Development of Critical Nursing Care Standards for Adult Surgical Patient thesis submitted for partial fulfillment of the requirements of the master degree in adult nursing, Faculty of nursing, Assiut University, Discussion part Pp. (87).

15. Smeltzer S., Bare B., Hinkle J., Philadelphia, P., Wolters Kluwer, Lippincott Williams \& Wilkins, (2010): Brunner \& Suddarth's
Textbook of Medical-Surgical Nursing; $12^{\text {th }}$ ed Pp.(465)

16. U.S. News \& World Report, (2009): Deep vein thrombosis (DVT)/ venous thromboembolism (VTE) prevention. Pp. (5).

17. University of Virginia health system (UVAHS) (2011): ensuring safe practice environment. EPINet / UVA's international health care worker safety center Pp. (120).

18. Zidarov D., Swaine B., \& Gauthier-Gagnon C., (2009): Quality of life of persons Arch Phys Med Rehabil; Pp. (634-645). 